\title{
What the papers say: How does the United Kingdom press treat water fluoridation and does it matter?
}

\author{
R. J. Lowry, ${ }^{1}$
}

This is a case study to investigate in an objective way how fluoridation is reported in the press. All press cuttings collected by a reputable national agency covering a 9-month period were studied; were rated as being profluoridation, antifluoridation or neutral. The rating system was calibrated before the study by comparing the scores given by the author and a selected group of experts. Overall, press article coverage was antifluoridation, though it is not clear how intentional this is.

$\mathrm{H}^{-1}$ ow newspapers cover issues familiar to us is the stuff of urban legends: while we might take in almost everything we read about other people's business uncritically, coverage of our own subject is rarely exemplary. But is this true for water fluoridation? Are we just being over-sensitive when we read anything less than full-scale support for the initiative in the papers, or is there evidence that reporting is more anti than pro? To test this, the author undertook a case study of the press reportage of water fluoridation and this forms the basis for discussion.

Water fluoridation is an effective, safe and cheap public health intervention. The safety and efficacy have been reviewed a

In brief

- A study of UK press coverage of the fluoridation issue between July 1988 and March 1999.

- This study uses a calibrated rating scale, there is a reversible antifluoridation bias.

- The anti bias is shared with other health promotion initiatives.

- How important the anti bias is and what can be done is debatable.

$1^{*}$ Senior Lecturer in Dental Public Health, Department of Child Dental Health, Dental School, University of Newcastle upon Tyne NE2 4BW

${ }^{*}$ Correspondence to: $R$. J. Lowry REFEREED PAPER

Received 17.06.99; ACCEPTED 02.11.99

(C) British Dental Journal 2000; 189: 14-18 number of times over the years and by diverse public health experts. ${ }^{1-15}$ It has been investigated more than similar public health measures such as the fortification of commercial flour with calcium. The impact on dental health is outstanding, preventing $50 \%$ of dental caries when consumed at one part per million. Yet implementation has been patchy: extensive in the United States of America in recent years, but limited to $10 \%$ of the population of the United Kingdom, although some schemes here have been in existence for more than 30 years.

Such an appalling failure to bring a proven benefit to suffering millions in the United Kingdom should surely be the stuff of campaigning journalists throughout the land: lack of government nerve and foresight, a handful of cranks dictating public policy to the detriment of the needy, yet another British 'invention' being exploited abroad, and so on. But with a few exceptions, this is not the usual line the papers take. According to them we are still agonising over safety and efficacy. So perhaps newspapers are part of the problem, slowing down progress by taking a particular (anti) line on the issue. Fluoridation does attract curious coverage, and no more so in newspapers. Some of the coverage is encouraging, some alarmist (Figure 1) some amusing (Figure 2), and some bizarre (Figure 3). No wonder that many public health advocates think the press is biased against fluoridation; but is it? The author undertook a case study to investigate in an objective way how fluoridation is reported in the press.

\section{Case study}

All the press cuttings collected by a reputable national agency and held by the British Fluoridation Society (BFS) covering a 9-month period (July 1998 to March 1999) were studied. This period was chosen as it represented a time midway between (and 4 months clear of) two central government policy discussion documents on public health including water fluoridation. The Green Paper (Our Healthier Nation) was published in February 1998, and indicated

\section{Is it another man's poison? \\ As a legal challenge is mounted to force Northumbrian Water to add flouride to drinking water IAN MARLAND asks why a question of public health should inflame public opinion}

Fig. 1 Newspaper headline concerning water fluoridation Newcastle Journal, July 1997 


\section{'Let Liverpool-the first city to appoint a Medical Officer of Health-again give a national lead to other great cities by fluoridating her water and let the slogan be What Liverpool drinks to- day-the rest of the country drinks to-morrow."}

\section{Fig. 2 Press cutting from Liverpool}

newspaper From: Spiegl F. Keep taking the tabloids: What the papers say and how they say it. p49. London: Pan, 1983.

the start of a consultation process that would end in a white paper (concrete proposals for implementation) during June/ July 1999. The cuttings agency reads all national daily and weekend papers published in the United Kingdom, as well as 900 regional paid-for papers. All material mentioning fluoride or fluoridation was included and sent to the BFS by the Borrow Dental Milk Foundation (BDMF) prior to this study (BDMF's address: Padmell Grange, Padmell Road, Portsmouth PO8 8ED). ${ }^{1}$ The agency
Fig. 3 Tongue-in-cheek book reference. From: Tuchell K. A-Z Conspiracy Theories. London: Summersdale, 1998

charges a fee-per-cutting and conducts internal and external audits to ensure high standards of retrieval.

The cuttings, sorted into monthly groups and copied for back-up purposes, were checked for duplication and extraneous material (for example cuttings from special interest or overseas publications). Each collection of monthly cuttings was then split into articles (including editorials and opin- ion columns) and letters-to-the-editor. All articles were coded and then detached from accompanying headlines to avoid bias as headlines are usually written by a subeditor, not the author.

All cuttings were then rated by the author as being profluoridation, antifluoridation or neutral. The rating system was calibrated before the study by comparing the score given to articles and headlines by

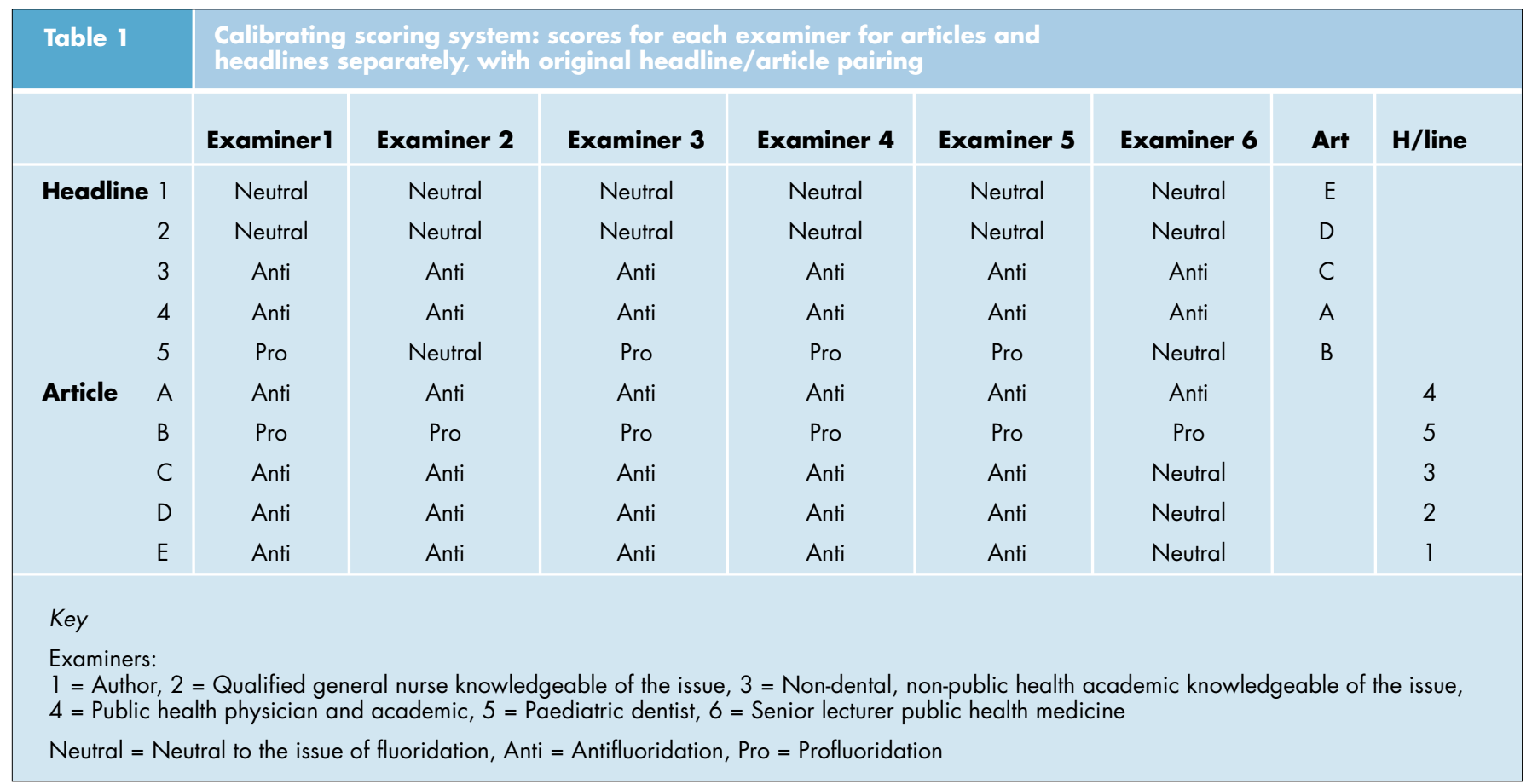




\begin{tabular}{|c|c|c|c|c|c|c|c|c|c|c|}
\hline \multirow[t]{2}{*}{ Table 2} & \multicolumn{10}{|c|}{ Analysis of newspoper cuttings by month } \\
\hline & July & August & September & $\begin{array}{l}98 \\
\text { October }\end{array}$ & November & December & January & $\begin{array}{l}1999 \\
\text { February }\end{array}$ & March & \\
\hline Cuttings & 19 & 32 & 27 & 25 & 75 & 42 & 46 & 9 & 48 & 323 \\
\hline Articles & 12 & 23 & 11 & 15 & 45 & 30 & 18 & 4 & 19 & 177 \\
\hline For & 5 & 7 & 4 & 3 & 27 & 5 & 6 & 1 & 5 & 63 \\
\hline Against & 7 & 15 & 4 & 10 & 10 & 14 & 9 & 3 & 10 & 82 \\
\hline Neutral & 0 & 1 & 3 & 2 & 8 & 11 & 3 & 0 & 4 & 32 \\
\hline Letters & 7 & 9 & 16 & 10 & 30 & 12 & 28 & 5 & 29 & 146 \\
\hline For & 1 & 1 & 0 & 0 & 2 & 1 & 2 & 0 & 0 & 7 \\
\hline Against & 6 & 8 & 16 & 10 & 28 & 11 & 26 & 5 & 29 & 139 \\
\hline
\end{tabular}

the author and a selected group of experts (Table 1, Figure 4). The author identified pro-, neutral and anti-fluoridation newspaper articles, detached their headlines and asked the experts to rate articles and headlines separately. The main analysis of cuttings concentrated on the body copy of articles, although letters-to-the-editor were also rated. More than 300 cuttings were analysed, comprising 177 articles and 146 letters-to-the-editor (Table 2). The majority of letters-to-the-editor were antifluoridation (139 against, 7 for). Of the 177 articles analysed, $46 \%$ were against fluoridation, $36 \%$ for and $18 \%$ neutral.

Overall, press article coverage was antifluoridation. The protagonist in the story usually determined the pro, neutral or anti angle; so a report of an antifluoridation rally generated an antifluoridation news item (Figure 4). Taking neutral and profluoridation articles together, the press were for fluoridation during September, November and December (percentage of profluoridation and neutral articles combined being 64, 77 and 53 respectively) and against in July, August, October February and March (percentage of profluoridation and neutral articles combined being 42, 35, 33, 25 and 47 respectively). The balance of pro-anti articles changed during the study period (Figure 5). During increased press coverage of the issue during November (1998), and to a smaller degree in January (1999), the usual small antifluoridation bias changed into a small bias in favour of fluoridation.

\section{Discussion}

\section{Method}

Before commenting on the results of this survey, it is important to discuss the method, particularly sampling, the rating system and examiner bias. With such a large and diverse press in the United Kingdom, it is almost inevitable that a complete sample of all fluoridation-related coverage will not be possible. For example, the so-called free newspapers have been excluded from this study, a lamentable if understandable omission given their proliferation over recent years. So conclusions from this study on the coverage of fluoridation at local level have to be made with extreme caution. Another weakness of the sampling method relates to its removal from the analysis: There is a potential for bias at the cuttings agency, the BDMF and the BFS or all three: the agency could have systematically under-reported material relating to fluoridation (which would not change the pro/anti fluoridation

\begin{tabular}{|l|l|} 
Headline $\mathbf{1}$ \\
Rated neutral by all examiners \\
Getting message on fluoride \\
Headline 5 \\
Rated profluoridation by four examiners, neutral by two. \\
'Fluoridate water' call is renewed \\
Headline D \\
Rated Antifluoridation by five examiners, neutral by one. \\
ANTI-FLUORIDE campaigners from Leicester- \\
shire joined a lobby in Birmingham. \\
The members of LARAF, Leicestershire and \\
Rutland Against Fluoridation, joined other \\
campaigners at the AGM of Severn Trent. \\
The water company does add fluoride to \\
water in other parts of the Midlands, but this is \\
done on the request of health authorities and \\
Leicestershire Health Authority has said there \\
are no plans to ask for fluoride. \\
Campaigners are worried that the issue is \\
likely to be discussed in the next few years and \\
are attempting to rally support. \\
\hline $\mathbf{4}$ Cutting examples with
\end{tabular}




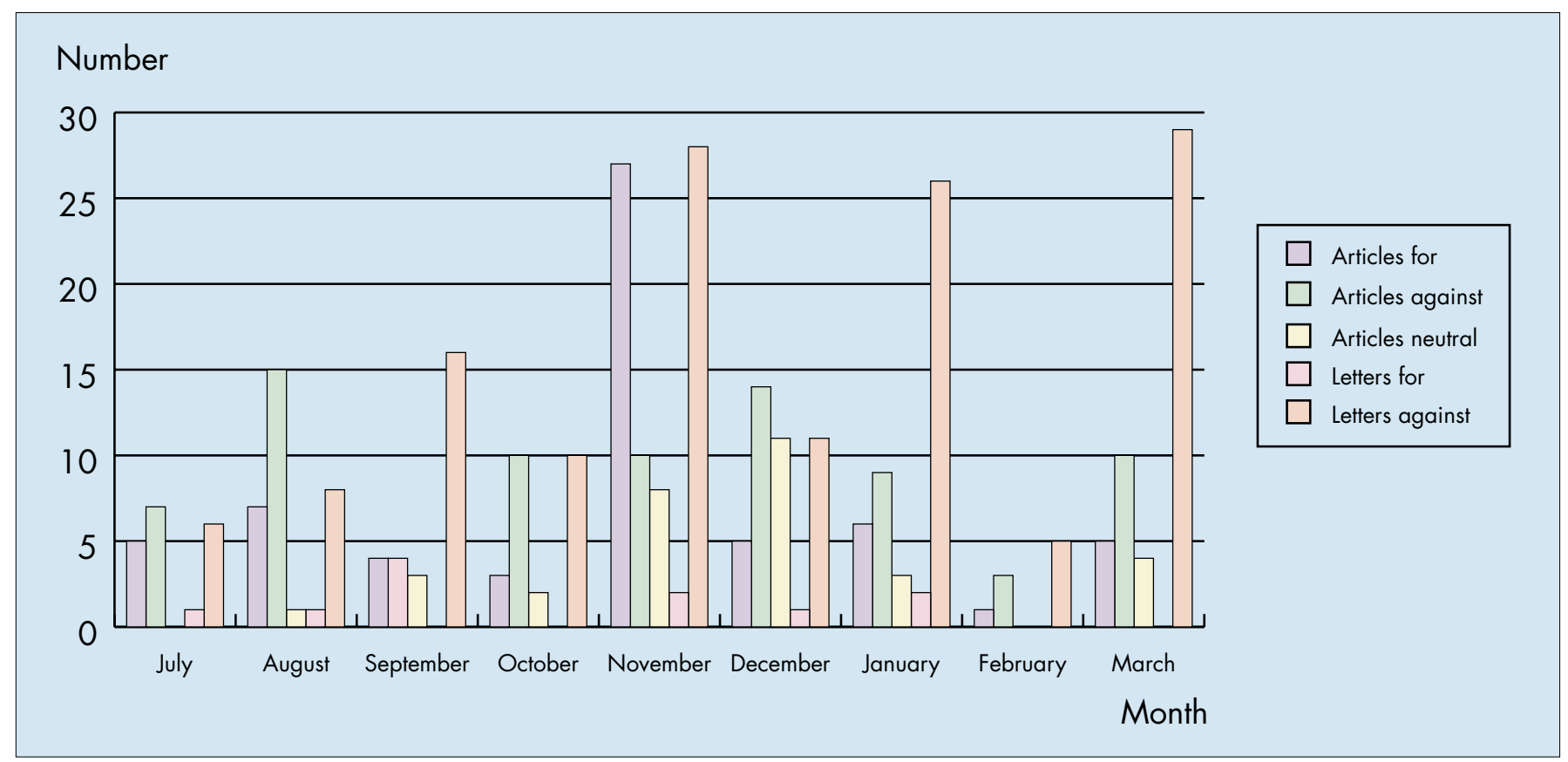

Fig. 5 Newspaper articles and letters on fluoridation by month

balance), but internal and external auditing should reduce or eliminate the source; and the BDMF and the BFS could have selectively withdrawn material to further their own cause, but only if they had known what the cuttings were to be used for.

Another methodological discussion point is the rating system. It is crude, especially when more sophisticated systems are available ${ }^{16,17}$ and have been used on similar material. ${ }^{18}$ A number of more sophisticated rating scales were considered but the simple one used was chosen because news articles in the press are often too simple to withstand sophisticated analysis; and more importantly, it could be argued that a crude rating scale is all that is needed for a crude transmitter of fact and opinion.

So what about examiner bias? Compared with the other examiners during calibration, the author tends to be more sensitive to antifluoridation bias (Table 1). Given that all the examiners are knowledgeable about fluoridation (and therefore more likely to be in favour), it could be speculated that a lay audience would rate the cuttings differently, tending towards neutrality (at least as far as the articles are concerned, as letters-to-the- editor are more explicitly opinionated). However, given the smallness and the weakness of the case against fluoridation, perhaps public health practitioners could have expected a much less 'even-handed', more profluoridation stance than was found.

Many of the above issues and concerns will be addressed in future research using more detailed scoring systems ${ }^{18}$ and direct, prospective data collection.

\section{Results}

If the sample is satisfactory and the bias correctly read, what do the results mean? Firstly, there is a low level of coverage of the issue (on average 15 a month over the UK); the interest peaked in November 1998 after a national campaign by the leading lobby group of more than 35 organisations in favour of fluoridation. Secondly, the press are more biased against than for fluoridation (although this represents only the perceived protagonists setting the news agenda, not necessarily biased writing). As this is reversible during active profluoridation campaigning, it probably represents continuous antifluoridation press lobbying. But thirdly, given the weight and strength of evidence for fluoridation, it cannot be solely antifluoridation lobbying; it suggests an inherent antifluoridation bias in certain journalistic circles. For example, one might expect an antifluoridation protagonist-lead story to be leavened by better coverage of the stronger profluoridation antagonist position in the story, not just served up in equal measure where the antagonist position dominates the story by virtue of its agenda-setting status.

This apparent tendency for the media to favour the antifluoridation (and anti-establishment) case and for this to have health adverse consequences is documented. For example, anti-immunisation press coverage has adversely affected immunisation uptake rates. ${ }^{18}$ Indeed, anti-immunisation feeling is almost de-rigeur in some journalistic circles, as this report of a conference illustrates:

'The audience, largely students of journalism and hence tomorrow's journalists, sent a ripple of contempt through the room when anyone sought to deflate the whistleblowing heroics of those who dared to question immunisation. For many there if an agent was imposed and promoted by doctors and drug 
companies, it must inevitably lead to a gruesome consequence. Many in health make the mistake of assuming journalists are natural conscripts to public health campaigns. While there are many happy coincidences between the stories that sell newspapers and those that alert communities to take health preserving actions, the attraction of anti-vaccine rhetoric shows that these values often cut the other way.' ${ }^{\prime 9}$

It should therefore be no surprise that fluoridation does not get the supportive national press one might expect knowing the strength of the case and its widespread support. It is relatively boring to mainstream journalists (personal communication), and so tends to be covered by journalists with limited experience who may be less able to see through antifluoridation propaganda (an opinion shared with journalism and press-officer colleagues). There is a small but vociferous antifluoridation lobby. The coverage of dentistry in the press is often stereotyped. And dental decay is now confined mainly to lower socio-economic groups who represent a small target population for the sale of newspapers and advertising space.

Does it matter that the press do not take a neutral stance? Perhaps not to the general public, who over the years have shown their continued support in regular opinion poll surveys. But two groups are likely to be very sensitive to a negatively biased press: water company boards and politicians. So it does matter if the press has a negative bias towards fluoridation, as present legislation on implementation of fluoridation schemes in the United Kingdom gives a veto to the boards of water companies, and future legislation could transfer that veto to local politicians.
How could the problems outlined in this case study be remedied? Alternatives include running a more proactive press campaign, supplying material to journalists refuting and exposing antifluoridation propaganda including quackery, ${ }^{20}$ and lobbying politicians to provide a clear policy lead including the necessary executive power to implement. There is also the need to undertake much more research into the media handling of such an important public health initiative as water fluoridation: this will include the contribution of letters-to-the-editor in press coverage, and, more importantly, the attitude of the broadcast media, arguably of increasing influence today.

No-one knows the power of the negative press highlighted in this article, or any matching bias in other media, but that should not be to underestimate the damage it could be doing.

1 Ministry of Health, Department of Health for Scotland, Ministry of Housing and Local Government. The fluoridation of domestic water supplies in North America as a means of controlling dental caries. Report of the United Kingdom Mission. London: HMSO, 1953.

2 World Health Organisation (1958) Report of Expert Committee on Water Fluoridation. Technical Report Series No 146. Geneva: World Health Organisation, 1958.

3 Ministry of Health, Scottish Office, Ministry of Housing and Local Government. The conduct of the fluoridation studies in the United Kingdom and the results achieved after five years. Reports on public health and medical subjects No. 105. London: HMSO, 1962.

4 Department of Health and Social Security, Scottish Office, Welsh Office. The fluoridation studies in the United Kingdom and the results achieved after eleven years. Reports on public health and medical subjects No. 122. London: HMSO, 1969.

5 World Health Organisation. Fluorides and human health. Geneva: World Health
Organisation Monograph Series No 59, 1970.

6 Royal College of Physicians. Fluoride Teeth and Health. Bath: Pitman Medical, 1976.

7 Clemmesen J. The alleged association between artificial fluoridation of water supplies and cancer: a review. Bull. World. Health. Organ. 1983; 61: 871-883.

8 Lord Jauncey. Opinion of Lord Jauncey in causa Mrs Catherine McColl (A.P.) against Strathclyde Regional Council. Edinburgh: The Court of Session, 1983.

9 Knox E G. Fluoridation of water and cancer: a review of the epidemiological evidence. London: HMSO, 1985.

10 Ad Hoc Subcommittee on Fluoride of the Committee to Co-ordinate Environmental Health and Related Programs. Review of Fluoride Benefits and Risks. Washington DC: Public Health Service, Department of Health and Human Services, USA, 1991.

11 Murray J J, Rugg-Gunn A J, and Jenkins G N. Fluorides in Caries Prevention. 3rd ed. Oxford: Wright, 1991.

12 National Health and Medical Research Council. The effectiveness of water fluoridation. Canberra: Commonwealth of Australia, 1991.

13 National Research Council: National Academy of Sciences Committee on Toxicology. Health effects of ingested fluoride. Washington DC: National Academy Press, 1993.

14 Expert Committee on Oral Health Status and Fluoride Use. Fluorides and oral health. WHO Technical Report Series No. 846. Geneva: World Health Organisation, 1994.

15 National Health and Medical Research Council. Review of water fluoridation and fluoride intake from discretionary fluoride supplements. Melbourne: Commonwealth of Australia, 1999.

16 Cardador M T, Hazan A R, Glantz S A. Tobacco industry smokers' rights publications: A content analysis. Am J Public Health 1995; 85: 1212-1217.

17 Oxman A D, Guyatt G H, Cook D J, Jaeschke R, Heddle N, Keller J. An index of scientific quality for health reports in the lay press. J Clin Epidem 1993; 46: 987-1001.

18 Leask J, Chapman S. An attempt to swindle nature: press reportage of anti-immunisation, Australia 1993-97. Aust NZ J Public Health 1998; 22: 17-26.

19 Chapman S. Tilting at the immunisation windmill. BMJ 1997; 314: 1646.

20 Brunette D M. Critical Thinking. pp53-62. London: Quintessence, 1996. 